\title{
Lung Cell Tropism and Inflammatory Cytokine-Profile of Porcine Respiratory Coronavirus Infection
}

\author{
K. Atanasova ${ }^{\mathrm{a}}$, S. Van Gucht ${ }^{\mathrm{a}, \#}$, F. Barbéa ${ }^{\mathrm{a}}$, D.J. Lefebvre ${ }^{\mathrm{a}}$, K. Chiers ${ }^{\mathrm{b}}$ and K. Van Reeth ${ }^{*, \mathrm{a}}$ \\ ${ }^{a}$ Laboratory of Virology, Faculty of Veterinary Medicine, Ghent University, Salisburylaan 133, B-9820 Merelbeke, \\ Belgium \\ ${ }^{b}$ Department of Pathology, Bacteriology and Avian Diseases, Faculty of Veterinary Medicine, Ghent University, \\ Salisburylaan 133, B-9820 Merelbeke, Belgium
}

\begin{abstract}
Knowledge about porcine respiratory coronavirus (PRCV) tropism was limited to morphological identification of target cells and controversial reports on replication in macrophages. This study aimed to clarify the lung cell tropism of a Belgian PRCV strain and to examine the lung profile of inflammatory cytokines for 15 days after intratracheal PRCV inoculation of gnotobiotic piglets. Until 5 days after inoculation, more than $50 \%$ of the PRCV-positive cells were type 2 pneumocytes, $30 \%$ bronchiolar epithelial cells, and $10 \%$ macrophages, as demonstrated by immunofluorescence stainings with specific cell markers. In vitro, PRCV productively infected primary porcine lung epithelial cells, but not porcine alveolar macrophages. Bronchoalveolar lavage fluids of PRCV-inoculated pigs contained high levels of interferons (IFN- $\alpha$, IFN- $\gamma$ ) and interleukin-6, moderate interleukin-12 and low tumour necrosis factor- $\alpha$ levels. Our results indicate that PRCV infects primarily type 2 pneumocytes and induces lower lung cytokine levels, compared to swine influenza virus or lipopolysaccharide-complicated PRCV infections.
\end{abstract}

Keywords: PRCV, lungs, type 2 pneumocytes, cytokines, alveolar damage.

\section{INTRODUCTION}

Porcine respiratory coronavirus (PRCV), a deletion mutant of the transmissible gastroenteritis virus (TGEV), emerged in Europe in the early 1980's [1]. Later, a similar virus was found in the USA $[2,3]$. PRCV has spread widely in the European swine population (reviewed in [4]). In 1989-1990 up to $90.6 \%$ of the pigs in Belgium were seropositive for PRCV [5]. At present, more than $95 \%$ of the Belgian swine herds are seropositive against PRCV (unpublished data).

TGEV replicates in the villous enterocytes of the small intestine and causes fatal enteritis in young pigs, whereas PRCV replicates in the respiratory tract and has lost its ability to replicate in enterocytes [6]. PRCV has been reported to replicate in a variety of lung cell types. The Belgian PRCV strain TLM83 was found in alveolar, bronchiolar and bronchial epithelial cells and in bronchoalveolar macrophages [6] whereas the USA strain AR310 was found mainly in epithelial cells in terminal bronchioli and to a lesser extent in type 2 pneumocytes and alveolar macrophages [7]. O'Toole et al. inoculated pigs with an English PRCV isolate (Stopps) and detected viral antigen only in non-ciliated cuboidal bronchiolar epithelial cells and alveolar macrophages [8]. Ahn et al. examined lung tissues from pigs inoculated with a Korean isolate of PRCV (SK2736). PRCV antigen was detected only

\footnotetext{
*Address correspondence to this author at the Laboratory of Virology, Faculty of Veterinary Medicine, Ghent University, Salisburylaan 133, B-9820 Merelbeke, Belgium; E-mail: kristien.vanreeth@Ugent.be

${ }^{\#}$ Current Address: Department Pasteur Institute, Scientific Institute of Public Health, Engelandstraat 642, B-1180 Brussels, Belgium
}

in alveolar interstitial macrophages [9]. In all these studies virus positive cells were detected by immunohistochemical methods or in situ hybridisation and the cells were identified by morphological criteria only.

Though PRCV replicates extensively in the lungs, and some experimental infection studies have resulted in respiratory disease [10-12], most experimental infections are subclinical $[1,6,8,13,14]$. We have previously shown that PRCV induces a different cytokine profile when compared to primary respiratory viral pathogens like swine influenza virus [14-16]. The latter virus induces much more rapid and higher production of a series of proinflammatory cytokines interferon- $\alpha$ (IFN- $\alpha$ ), interleukin-1 (IL-1), IL-6 and tumour necrosis factor- $\alpha(\mathrm{TNF}-\alpha)$ - after intratracheal inoculation and this may explain the much more prominent respiratory disease as compared to PRCV $[14,15]$. In previous studies, however, cytokines were only examined during the first 3-4 days after inoculation with PRCV. IFN- $\gamma$ is a pleiotropic cytokine involved in the regulation of nearly all phases of the immune and inflammatory responses, including the activation, growth and differentiation of T-cells, B-cells, macrophages, NK cells and other cell types such as endothelial cells and fibroblasts (reviewed in [17]). IL-12 plays a central role in bridging the cellular and humoral branches of the innate and antigen-specific adaptive immunity (reviewed in $[18,19])$. It is produced primarily by antigen-presenting cells and is best known for its ability to induce IFN- $\gamma$ production by these cells. IL-12 also synergizes with other cytokines and lymphocyte-activating agents, including TNF- $\alpha$ and IL1 , in the induction of IFN- $\gamma$. IFN- $\gamma$ and IL-12 (via IFN- $\gamma$ induction) have also been shown to have antiviral effects against encephalomyocarditis virus in mice in vivo [20] and 
against porcine respiratory and reproductive syndrome virus in vitro in porcine pulmonary alveolar macrophages [21]. Despite their antiviral effects and importance in the host immune responses, IFN- $\gamma$ and IL-12 have not previously been examined during PRCV infection.

This study aimed to gain better insights in the cell tropism of a Belgian strain of PRCV and answer the question whether the virus replicates in macrophages. To this purpose we used two approaches: 1) we determined the target cells in the lungs of infected pigs in vivo by using cell-specific markers, 2) we compared the replication of PRCV in primary porcine lung epithelial cells and in alveolar macrophages in vitro. A second aim was to study the evolution of several proinflammatory cytokines over the entire course of PRCV infection with an emphasis on IFN- $\gamma$ and IL-12, which have not yet been examined during PRCV infection. We also tried to find an association between severity of disease, pathology and cytokine levels during PRCV infection.

\section{MATERIALS AND METHODS}

Pigs, Virus, Experimental Design and Sampling. Twenty-nine caesarean-derived colostrum-deprived pigs at the age of 3.5 weeks were used. The pigs originated from 3 conventional sows and were housed in individual Horsefalltype isolation units.

Twenty-six pigs were inoculated intratracheally with $10^{7}$ $50 \%$ tissue culture infective doses $\left(\mathrm{TCID}_{50}\right) \mathrm{PRCV}$ and euthanized at $1(\mathrm{n}=3), 2(\mathrm{n}=3), 3(\mathrm{n}=3), 4(\mathrm{n}=3), 5(\mathrm{n}=$ 3), $7(\mathrm{n}=3), 9(\mathrm{n}=3), 12(\mathrm{n}=3)$ and $15(\mathrm{n}=2)$ days post inoculation (DPI). The Belgian PRCV isolate 91V44 was used at the second passage in swine testis (ST) cells [22]. Virus was diluted in sterile pyrogen-free phosphate-buffered saline (PBS, Gibco) to obtain a $3 \mathrm{ml}$ inoculum. Three pigs were mock-inoculated with PBS and euthanized at 1, 7 and 15 DPI, respectively.

The right lung was used for lung lavage. Collection and concentration of bronchoalveolar lavage (BAL) fluids were performed as described previously [14]. Tissue samples from the apical, cardiac and diaphragmatic lobes of the left lung were collected for virological examinations, immunofluorescence stainings and histopathology. Serum from all pigs was collected at euthanasia.

The animal experiments described in this study were authorized and supervised by the Ethical and Animal Welfare Committee of the Faculty of Veterinary Medicine of Ghent University (EC2003/53, EC2004/40).

Clinical Scoring System and Assessment of Lung Lesions. The pigs were monitored daily for clinical signs. A score was given for the respiratory rate $(0:<60,1: 60-90$ mild tachypnoea, 2: $>90$ severe tachypnoea), abdominal thumping ( 0 : absent, 1 : present), dyspnoea ( 0 : absent, 1 : present), anorexia (0: absent, 1: present) and depression (0: absent, 1: present). The total score per pig was obtained by adding the scores for each parameter and ranged from 0 to 6 . Mean clinical scores were obtained as a mean of all pigs observed at each time point. The total number of pigs at each time point varied from 26 at the start of the experiment to 2 at day 15 as explained higher.

The gross lung lesions were drawn as accurately as possible onto a lung diagram and approximate percentage of affected lung area was arbitrarily assessed. For histopathological examination, samples of the cardiac and diaphragmatic lung lobes were fixed in $10 \%$ buffered formalin, embedded in paraffin, sectioned and stained with haematoxylin and eosin. A score was given for the extent of thickening of interalveolar septum, infiltration of neutrophils in different lung compartments, desquamation of bronchial and bronchiolar epithelial cells and disruption of the alveolar lining. Scores ranged from - (absent) to +++ (severe).

Virological Examinations in PRCV Inoculated Pigs. The amount of infectious PRCV was examined in lung tissue homogenates of pooled samples of apical, cardiac and diaphragmatic lung lobes. Twenty percent homogenates were prepared and titrated in ST cells according to standard procedures [22]. The detection limit of the assay was $10^{1.7}$ $\mathrm{TCID}_{50} / \mathrm{g}$ tissue.

Two-colour immunofluorescence stainings were performed on lung tissue sections of the cardiac and diaphragmatic lobes for identification and quantification of PRCV antigen-positive cells. A total area of $10 \mathrm{~mm}^{2}$ lung tissue was examined for each pig. The technique for two-colour immunofluorescence stainings has been described in detail elsewhere [23]. PRCV antigens were detected with biotinylated, purified monospecific porcine polyclonal antibodies $(\mathrm{pAb})$ against PRCV or biotinylated monoclonal antibody (mAb) against the spike protein (1BB11) [24], followed by fluorescein isothiocyanate (FITC)-labelled streptavidin (Molecular Probes, Eugene, Oregon, USA). PRCV antigen-positive cells were phenotyped using mouse $\mathrm{mAb}$ against sialoadhesin (mAb 41D3) and cytokeratin 18 (mAb CY-90, Sigma-Aldrich, St. Louis, USA), or rabbit pAb against porcine surfactant protein B (SP-B, Hycult biotechnology, Uden, The Netherlands), followed by Texas Red-labelled goat-anti-mouse pAb (Molecular Probes, USA) or biotin-labelled goat-anti-rabbit $\mathrm{mAb}$ (Sigma) and Streptavidin-Texas Red (Molecular Probes, USA) respectively. Sialoadhesin is expressed exclusively on the membrane of lung macrophages [25]. Cytokeratin 18 is expressed by bronchiolar epithelial cells and type 2 pneumocytes [26]. Surfactant protein B is a marker for type 2 pneumocytes [27]. Differentiation between bronchial, bronchiolar and alveolar epithelial cells in the dual stainings against cytokeratin 18 and PRCV were determined on basis of localisation, since the bronchi and bronchioli were readily visible. Specificity of the double stainings was determined by use of irrelevant mouse mAbs, porcine pAbs and rabbit pAbs. Digital images were taken using a Leica TCS SP2 laser scanning spectral confocal system linked to a Leica DM IRB inverted fluorescence microscope (Leica Microsystems GmbH, Wetzlar, Germany).

PRCV Replication in Lung Macrophages In Vitro. Pulmonary alveolar macrophages (PAMs) were isolated from the lungs of 4-week-old conventional piglets as previously described [28]. PAMs were seeded at a concentration of $10^{6}$ cells $/ \mathrm{ml}$ in 24-well plates, in RPMI (Gibco) containing 0.3 $\mathrm{mg} / \mathrm{ml}$ glutamine (Merck), $100 \mathrm{U} / \mathrm{ml}$ penicillin and $0.1 \mathrm{mg} / \mathrm{ml}$ streptomycin (P/S) (Pen Strep, Gibco), $0.1 \mathrm{mg} / \mathrm{ml}$ kanamycin (Kela laboratories) and 5\% foetal bovine serum (FBS, Gibco). The cells were cultured overnight $\left(37^{\circ} \mathrm{C}, 5 \% \mathrm{CO}_{2}\right)$ and were then inoculated with PRCV at a multiplicity of infection (m.o.i.) of 1, during one hour, followed by washing and addition of new medium. Culture media were harvested at 0 (after 
washing), 4, 8, 12, 24, 48 and 72 hours after virus inoculation (HPI) and centrifuged at $400 \times \mathrm{g}$ for $10 \mathrm{~min}$. The supernatants were used for determination of extracellular virus titres in ST cells. The detection limit was $10^{1.3} \mathrm{TCID}_{50} / \mathrm{ml}$ of cell culture medium. The intracellular virus titres and virus inactivation curves were determined as described elsewhere [29]. Experiments were repeated independently with macrophages from three different pigs.

PRCV Replication in Primary Lung Epithelial Cells In Vitro. Porcine primary lung epithelial cells were isolated from the lungs of 4-week-old conventional piglets using a procedure based on the method described by Lin et al. for isolation of primary equine respiratory tract epithelial cells [30]. The lungs were washed, minced and digested according to the original procedure. The remaining lung pieces were further digested with trypsine $\left(0.33 \%\right.$ in PBS) for 1 hour at $37^{\circ} \mathrm{C}$, followed by collection, filtration, trypsine inactivation and centrifugation as described in the original article. The obtained cells were washed with L-15 medium containing $10 \%$ FBS and seeded at $10^{6}$ cells $/ \mathrm{ml}$ in $175 \mathrm{~cm}^{2}$ tissue culture flasks in culture medium (as described in the original article, but further supplemented with $\mathrm{P} / \mathrm{S}$ and $2.5 \mathrm{mg}$ gentamycine). The cells were cultivated for 3 days at $37^{\circ} \mathrm{C}$ and $5 \% \mathrm{CO}_{2}$. The obtained cell culture was purified from fibroblasts using the following procedure: detachment of fibroblasts by incubation with $0.44 \%$ sodium-citrate in sterile ultra-purified water containing $1 \mathrm{~g} / 100 \mathrm{ml}$ potassium chloride, and subsequent washing with $\mathrm{P} / \mathrm{S}$-supplemented PBS. The epithelial cells were then detached for 10 minutes with $0.25 \%$ trypsine-EDTA solution, followed by trypsine neutralization with $2 \mathrm{ml}$ FBS and centrifugation for 10 minutes at $259 \mathrm{x} \mathrm{g}$. The cells were seeded at a density of $10^{5} / \mathrm{ml}$ in culture medium, and incubated for further 3 days, when the above-described purification procedure was repeated. The cells were seeded again at $10^{5} / \mathrm{ml}$ in $24-$ well-plates and when a monolayer was formed they were inoculated with PRCV at an m.o.i. of about 0.67 , for 1 hour at $37^{\circ} \mathrm{C}$. All wells were subsequently washed and new medium was added. The cell medium and intracellular virus were collected at $0,4,8,12,24,48$ and $72 \mathrm{HPI}$ as described above for
PAMs and titrated in ST cells. The experiment was repeated independently with lung tissue of two different pigs.

Quantification of Proinflammatory Cytokines in BAL Fluids. IFN- $\alpha$, IL- 6 and TNF- $\alpha$ in BAL fluids of PRCV inoculated pigs were quantified by bioassays as described elsewhere $[14,31,32]$. IFN- $\gamma$ was measured by an ELISA kit for swine IFN- $\gamma$ (Biosource, Nijvel, Belgium). IL-12 was measured in a DuoSet ELISA kit detecting the common p40 subunit of both IL-12 and IL-23 (R\&D systems, Abingdon, UK). Since IL-12 and IL-23 bind also to a common receptor chain and have similar proinflammatory activities ([33, 34] and reviewed in [35]) we did not examine them separately.

Lymphocyte Quantification in BAL Fluids. Total cell numbers were counted and the percentage of CD3- and IgMpositive cells was determined using flow cytometric analysis (Becton Dickinson FACSCalibur ${ }^{\mathrm{TM}}$, BD Cellquest software) as described earlier [23]. CD3 (mAb PPT3) is expressed on Tlymphocytes and IgM (mAb 28.4.1) on B-lymphocytes [36, 37].

Antibody Titration. PRCV-neutralizing antibodies in sera were titrated using a virus-neutralization assay as described by Voets et al. [38].

\section{RESULTS}

Clinical Signs. The first 4 days of infection most pigs showed no clinical signs. Five pigs had mild symptoms (score 1 ), characterized by abdominal thumping or increased breathing rates (60-90 breaths/minute) and one exceptional pig developed severe respiratory symptoms with a score of 6 at 3 and 4 DPI. At later stages of infection (5-8 DPI) more pigs showed one or more clinical signs. Seven DPI 7 of the total 11 remaining pigs showed severe tachypnoea ( $>90$ breaths/minute), dyspnoea, depression and/or anorexia and the mean clinical score (1.2) peaked. Coughing was occasionally observed between 4 and 8 DPI and individual clinical scores never exceeded 5. From 9 DPI onwards, most pigs had completely recovered.

Table 1. Evolution of Macroscopical and Microscopical Lung Lesions in Pigs Throughout PRCV Infection

\begin{tabular}{|c|c|c|c|c|c|}
\hline \multirow{2}{*}{$\begin{array}{c}\text { Days Post Inoculation } \\
\text { with PRCV }\end{array}$} & \multirow{2}{*}{$\begin{array}{c}\text { Mean \% of Lung Surface } \\
\text { with Lesions (Range) }\end{array}$} & $\begin{array}{c}\text { Infiltration of } \\
\text { Neutrophils }\end{array}$ & $\begin{array}{c}\text { Extent of Morphological Changes in Lung Tissue } \\
\text { Thickening of } \\
\text { Interalveolar Septa }\end{array}$ & $\begin{array}{c}\text { Desquamation of Bronchial and } \\
\text { Bronchiolar Epithelial Cells }\end{array}$ & $\begin{array}{c}\text { Destruction of } \\
\text { Alveolar Walls }\end{array}$ \\
\hline \hline 1 & 0 & + & + & + & ++ \\
\hline 2 & $4(3-5)$ & + & ++ & + \\
\hline 3 & $9(3-16)$ & + & ++ & ++ \\
\hline 4 & $33(3-75)$ & + & ++ & + \\
\hline 5 & $19(10-26)$ & + & ++ & + \\
\hline 7 & $41(30-52)$ & + & + & + \\
\hline 9 & $22(5-53)$ & - & + & + & + \\
\hline 12 & $1(0-2)$ & - & + & + \\
\hline 15 & $1(0-2)$ & - & + & + \\
\hline
\end{tabular}

${ }^{\mathrm{I}}$ Twenty-six 3.5-week-old pigs were inoculated intratracheally with $10^{7} \mathrm{TCID}_{50}$ of PRCV and euthanized ( $\mathrm{n}=3$; except $\mathrm{n}=2$ at 15 days post inoculation) at selected time intervals. ${ }_{-}^{2}=$ absent; $+=$ mild; $++=$ moderate; $+++=$ severe.

${ }^{3}$ Infiltration of neutrophils was observed in bronchi, bronchioli, and alveolar interstitium. 
None of the negative control pigs showed any clinical symptoms at any time post PBS inoculation until euthanasia.

Lung Lesions. Table 1 and Fig. (1) show the evolution of lung lesions throughout infection. Macroscopically visible lesions were characterized by dark-red consolidation, covering 3 to $75 \%$ of the lung surface. The apical, cardiac and accessory lobes of the right lung tended to be most affected. Consolidation of lung tissue was visible starting from 2 DPI, but was most extensive between 4 and 9 DPI, with a mean of 19 to $41 \%$ of the total lung surface affected (3 to $75 \%$ individual variation). Microscopical lesions were characterized by bronchointerstitial pneumonia at all examined time points. Typically, interalveolar septa were thickened because of infiltration of monomorphonuclear cells. Presence of neutrophils in bronchial lumina and alveolar septa was observed 1 to 7 DPI. During the first 2 DPI, the alveolar lining generally appeared intact. At later stages ( $>2$ DPI) the alveolar lining was no longer intact and alveoli contained cellular debris and proteinaceous fluid. These lesions were most pronounced at 7 DPI. Lung lesions were not observed in any of the PBS inoculated control pigs.

Evolution of Virus Titres. Fig. (2) shows the evolution of virus replication in the lungs. Infectious virus was detected from 1 to 9 DPI. Most virus was produced during the first 5 days of infection. Mean virus titres reached up to $10^{7}$ $\mathrm{TCID}_{50} / \mathrm{g}$ lung tissue during the first 4 days, decreased by 1.7 $\log 10$ on 5 DPI and by $3.4 \log 10$ on 7 DPI. Nine DPI, only one out of 3 pigs tested virus-positive $\left(10^{2.3} \mathrm{TCID}_{50} / \mathrm{g}\right.$ lung tissue). Virus was not detected in any of the control pigs.

Identification of PRCV-Target Cells. One day after intratracheal inoculation of pigs with PRCV, about $60 \%$ of the infected cells in the lungs were type 2 pneumocytes and $30 \%$ were bronchiolar epithelial cells. At later time points, infected bronchiolar epithelial cells became rare and the vast majority of infected cells $(90 \%)$ were type 2 pneumocytes (Figs. 2 and 3). Viral antigens were also found in macro- phages (about $10 \%$ of positive cells). The fluorescence pattern in macrophages differed from that in epithelial cells (Fig. 3). Macrophages contained PRCV-positive granules of varying size in their cytoplasm, whereas the cytoplasm of epithelial cells stained more uniformly for viral antigens. Positive macrophages were often surrounded by PRCVpositive debris.

The growth curves of PRCV in porcine alveolar macrophages and in primary lung epithelial cells are given in Fig. (4). We were unable to demonstrate production of infectious progeny virus after in vitro inoculation of alveolar macrophages, in contrast to primary porcine lung epithelial cells, in which we detected high virus yields. In macrophages extraand intracellular virus titres decreased in a time-dependent manner while PRCV titres in primary porcine lung epithelial cells increased from $10^{2.0} \mathrm{TCID}_{50} / \mathrm{ml}$ at $4 \mathrm{HPI}$ up to $10^{5.8}$ $\mathrm{TCID}_{50} / \mathrm{ml}$ at $72 \mathrm{HPI}$.

Proinflammatory Cytokines in BAL Fluids. Fig. (5) shows the evolution of IFN- $\alpha$, IFN- $\gamma$, IL-6, IL-12 and TNF$\alpha$. Cytokines were undetectable in the BAL fluids of PBSinoculated control pigs, except for one pig, which had a low titre of IL-6 $(58 \mathrm{U} / \mathrm{ml})$.

After PRCV infection, high titres of IFN- $\alpha$ and IL- 6 were found in all pigs between 1 and 5 DPI (mean titres between 3637 and $80481 \mathrm{U} / \mathrm{ml}$ for IFN- $\alpha$, and between 3621 and 20480 $\mathrm{U} / \mathrm{ml}$ for IL-6), after which the titres decreased and by day 15 IFN- $\alpha$ and IL- 6 were no-longer detectable. In contrast, titres of TNF- $\alpha$ were low and were detectable only between 1 and 3 DPI (mean titres between 246 and $296 \mathrm{U} / \mathrm{ml}$ ). High IFN- $\gamma$ levels were found from 1 to 7 DPI (mean titres between 85 and $1138 \mathrm{pg} / \mathrm{ml}$ ), whereas only very low levels were detected between 9 and 15 DPI (mean titres between 4 and $6 \mathrm{pg} / \mathrm{ml}$ ). IL-12 levels in the BAL fluids peaked between 1 and 5 DPI (mean titres between 1810 and $8560 \mathrm{pg} / \mathrm{ml}$ ) and slowly decreased until 15 DPI when they were no longer detectable.

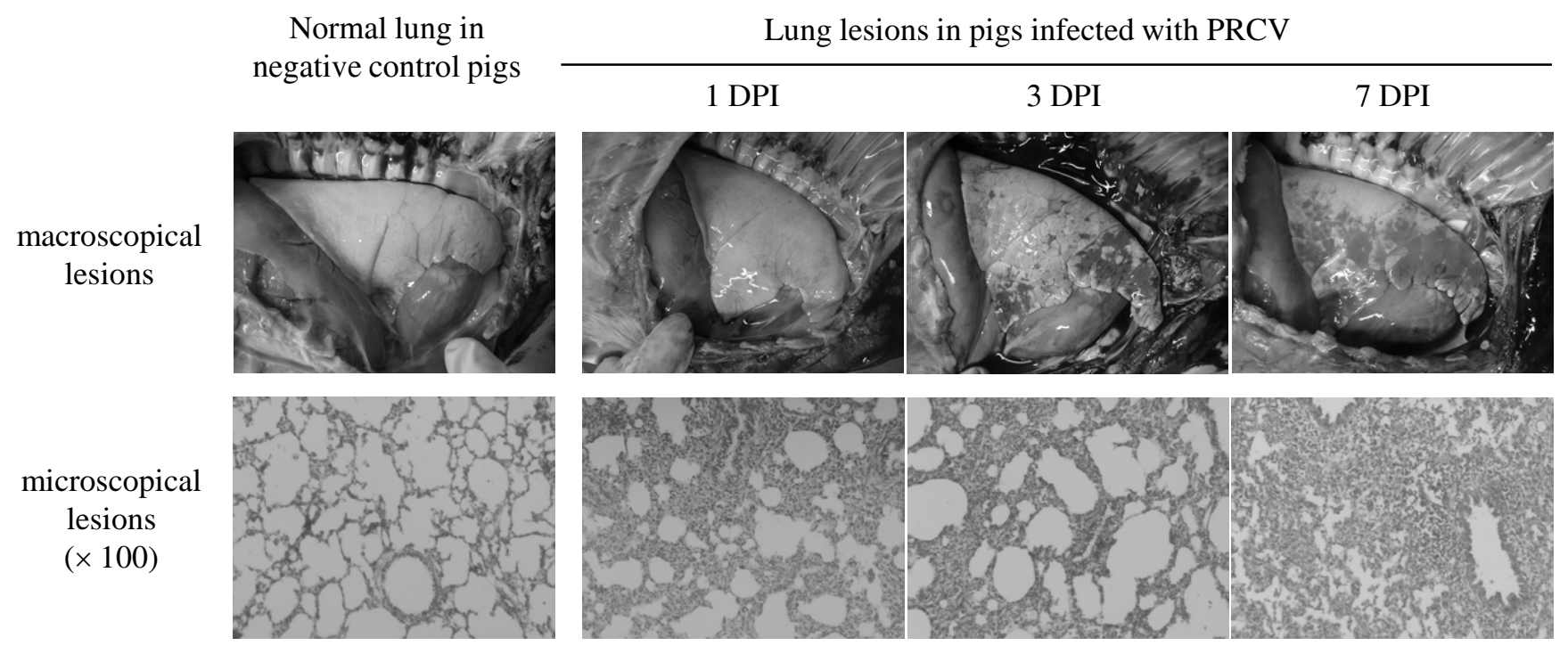

Fig. (1). Evolution of lung lesions during PRCV infection. Macroscopical lesions included dark-red consolidation of lung tissue and were mostly found in apical and cardiac lung lobes. At 1 and 3 days post inoculation (DPI), thickening of interalveolar septa was the most prominent microscopical lesion. The alveolar lining appeared intact. At 7 DPI, large foci of alveolar destruction were found in the lungs. 


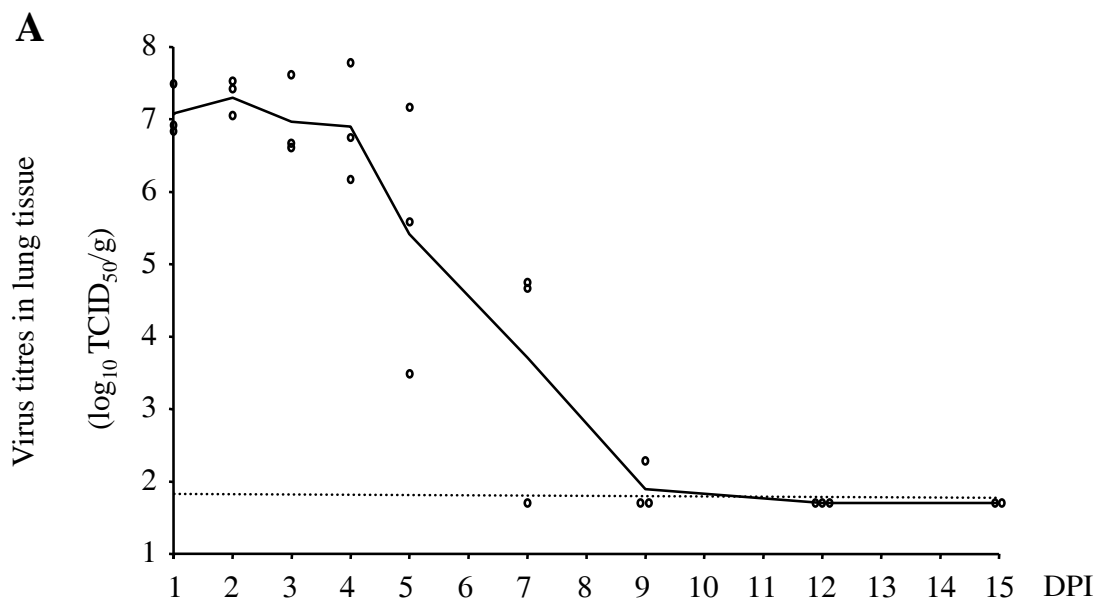

B

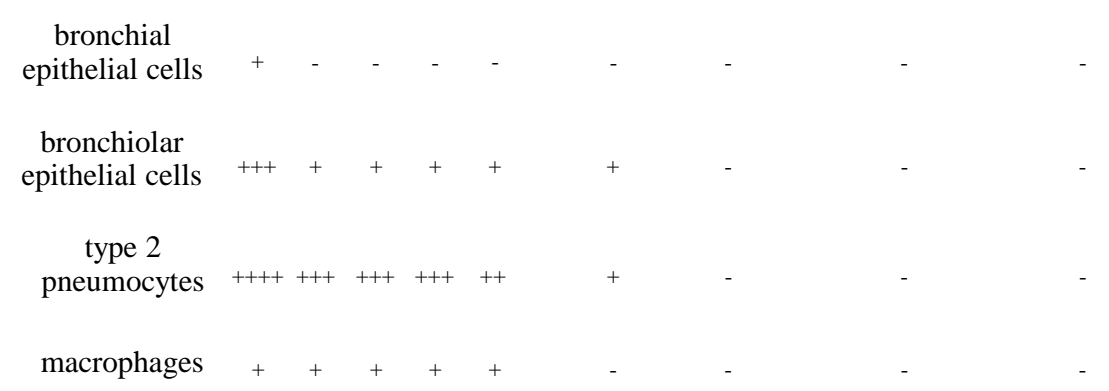

Fig. (2). Evolution of virus titres (A) and different types of PRCV antigen-positive cells (B) in the lungs of pigs throughout infection. The dots represent the individual virus titres, whereas the full line represents the mean titre. The detection limit of the assay is given as dotted line. PRCV-positive cells were identified with markers for type 2 pneumocytes (cytokeratin $18^{+}$, surfactant protein $\mathrm{B}^{+}$), bronchiolar epithelial cells (cytokeratin $18^{+}$) and macrophages ( sialoadhesin $^{+}$). The amount of PRCV-positive cells was scored as follows: $-=0$ cells $/ \mathrm{mm}^{2},+=1-$ 10 cells $/ \mathrm{mm}^{2},++=11-200$ cells $/ \mathrm{mm}^{2},+++=201-400$ cells $/ \mathrm{mm}^{2},++++=>400 \mathrm{cells} / \mathrm{mm}^{2}$.

Lymphocyte Counts and Neutralizing Antibodies. Fig. (6) shows the evolution of lymphocyte numbers in BAL fluids and neutralising antibodies in sera. Mean numbers of Tlymphocytes and B-lymphocytes in the BAL fluids of control pigs were respectively $1.4 \times 10^{6}$ and $0.6 \times 10^{6}$, whereas in the PRCV infected pigs mean T- and B-lymphocyte numbers increased from 3 DPI onwards, peaked at 9 DPI (for Tlymphocytes: $68 \times 10^{6}$ ) and at 7 and 9 DPI (for Blymphocytes: $11 \times 10^{6}$ ), and remained elevated until $15 \mathrm{DPI}$. The PBS control pigs had no antibodies against PRCV, whereas in the PRCV-inoculated pigs anti-PRCV antibodies were detected in 2 out of 3 animals euthanized at 5 DPI, and in all pigs euthanized at later time points.

\section{DISCUSSION}

In this study we had two main aims. Firstly, we wanted to examine in detail the cellular tropism of a Belgian strain of PRCV, 91V44, and in particular its ability to replicate in alveolar macrophages. Secondly, we intended to complete the profile of previously examined cytokines over the entire course of PRCV infection, and in addition to study the evolution of two inflammatory cytokines that have not previously been examined during PRCV infection - IFN- $\gamma$ and IL12.

Our results suggest that the type 2 pneumocyte is the major target cell for PRCV replication in the lungs. Type 2 pneumocytes constitute $60 \%$ of the alveolar cells, though they comprise only $4 \%$ of the alveolar surface area [39]. This cell type plays an important role in normal lung function and homeostasis by producing surfactant, regulating the intraalveolar fluid balance and taking part in the regeneration of the alveolar epithelium following injury [40]. Besides in type 2 pneumocytes, PRCV antigens were also found in the cytoplasm of bronchiolar epithelial cells and macrophages. Infected bronchi were found only during the first day of infection and were rare at later time points. This is in agreement with previous findings with the European PRCV strain TLM83 [6]. Though we found PRCV-positive macrophages, they constituted only about $10 \%$ of the positive cells. Furthermore we have indications that the macrophages did not support a productive viral infection and that they became positive for PRCV antigens after phagocytosis of viral antigen-contaminated debris. The positive macrophages were often surrounded by such debris and had a typical irregularly granulated staining in their cytoplasm. In addition, primary alveolar macrophages could not sustain a productive infection with our PRCV strain in vitro, whereas we obtained relatively high viral yields in primary lung epithelial cells in vitro (Fig. 4). This is in contrast to previous studies with TGEV [41] in cultured primary alveolar macrophages, where three cell-adapted strains of TGEV (Purdue 115, $\mathrm{D}_{52}-5$ and 6386-5) were shown to replicate extensively (up to $5 \times 10^{5}$ plaque forming units $/ \mathrm{ml}$ ) and cause cell death in up to $75 \%$ of the cells within $24 \mathrm{HPI}$. Our data also contrast to those of Ahn et al. [9]. Based on morphological analysis of immunohistochemical staining of infected lung tissue, they 
a

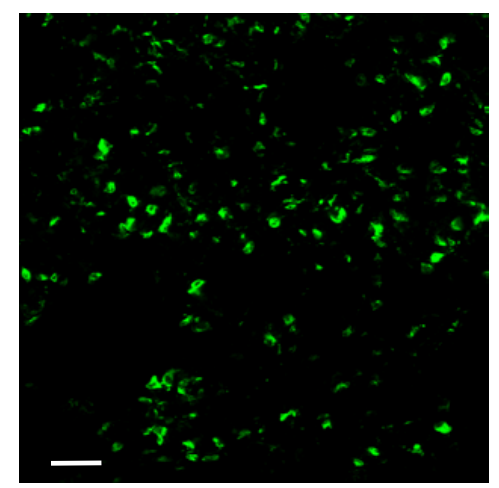

b

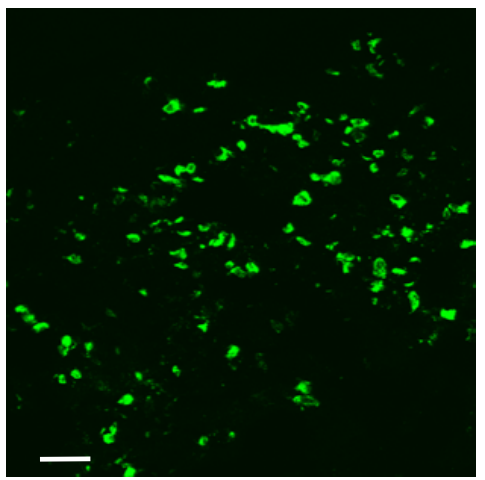

C

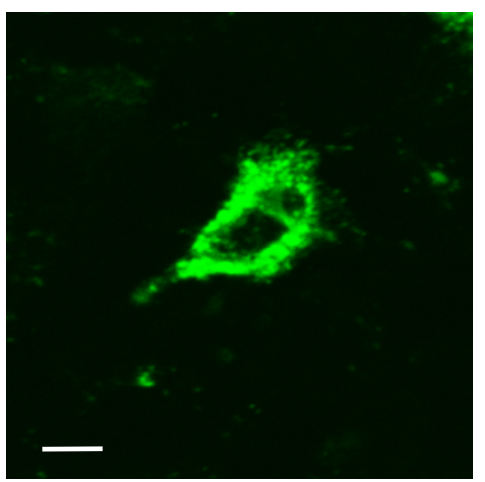

d

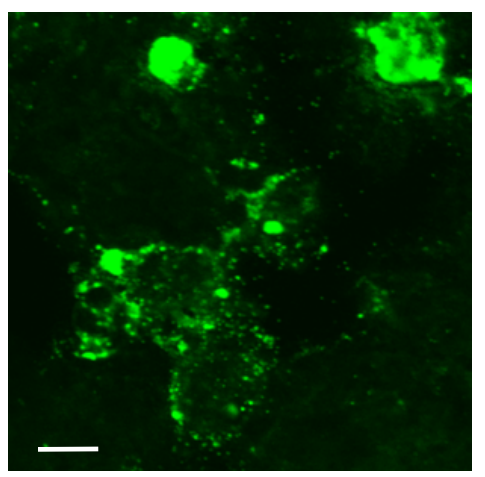

cytokeratin 18

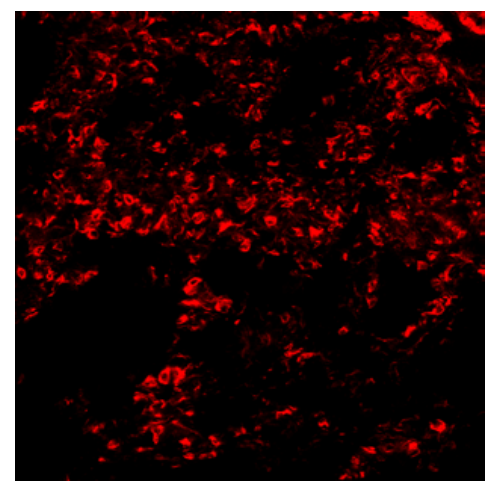

surfactant protein B

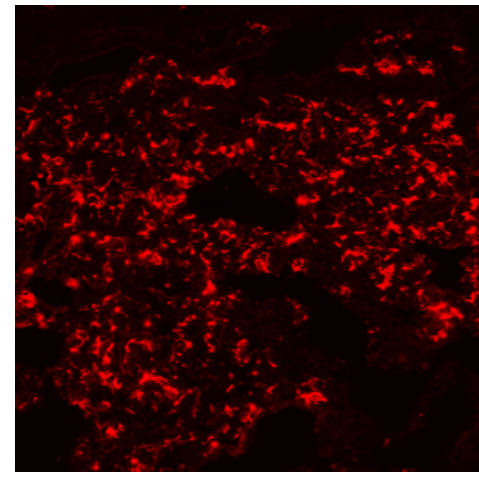

surfactant protein B

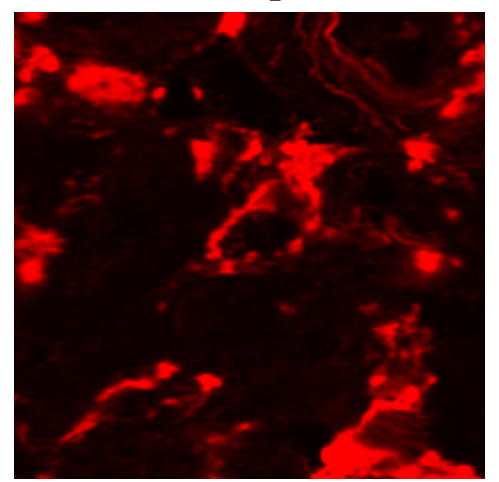

sialoadhesin

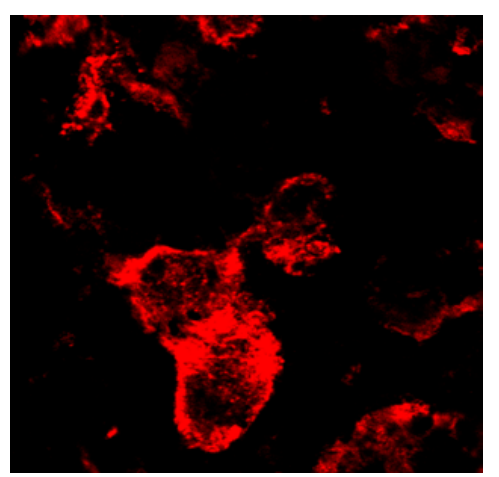

overlay

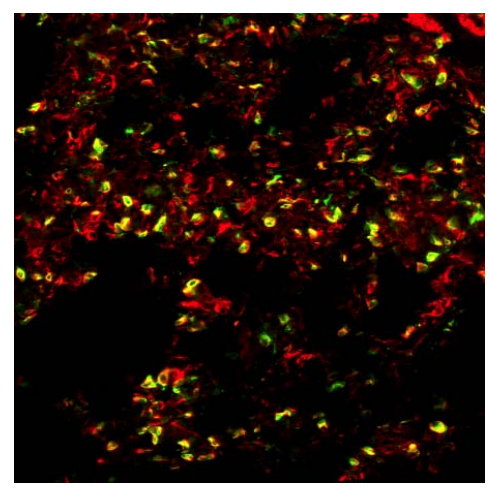

overlay

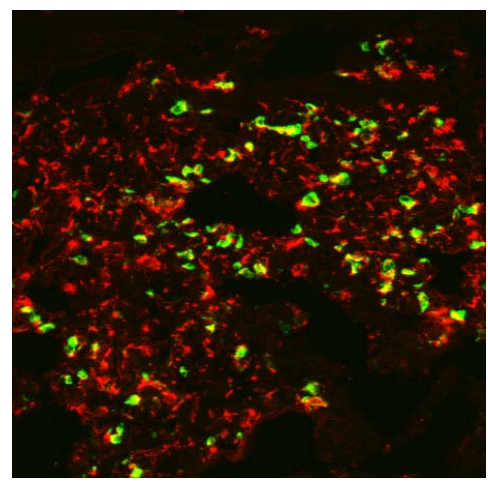

overlay

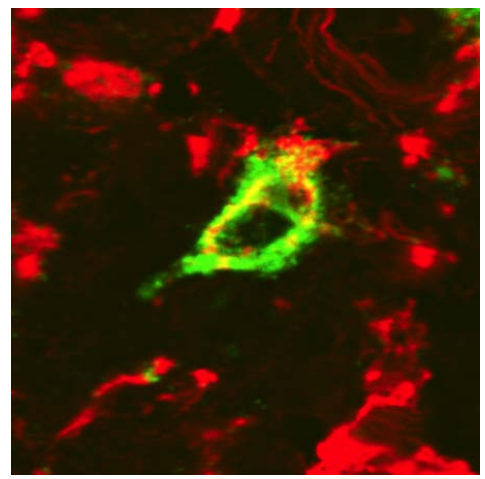

overlay

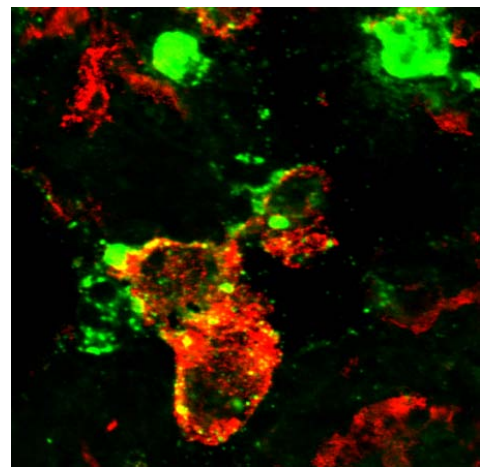

Fig. (3). Two-color immunofluorescence staining for PRCV antigens and markers for different cell types in porcine lungs at 2 DPI with PRCV. Most PRCV-positive cells were type 2 pneumocytes. (a) $(\mathrm{bar}=50 \mu \mathrm{m})$ illustrates that more than $90 \%$ of the PRCV-positive cells expressed cytokeratin 18. (b) $(\mathrm{bar}=50 \mu \mathrm{m})$ and $(\mathbf{c})(\mathrm{bar}=10 \mu \mathrm{m})$ show that PRCV-positive cells expressed surfactant protein $\mathrm{B}$, which is a secretion product of type 2 pneumocytes. PRCV antigens were occasionally found in sialoadhesin-positive macrophages $(\mathbf{d})(\mathrm{bar}=10 \mu \mathrm{m})$. PRCV staining in these cells had a granular pattern and positive macrophages were typically surrounded by viral antigen-positive debris. 

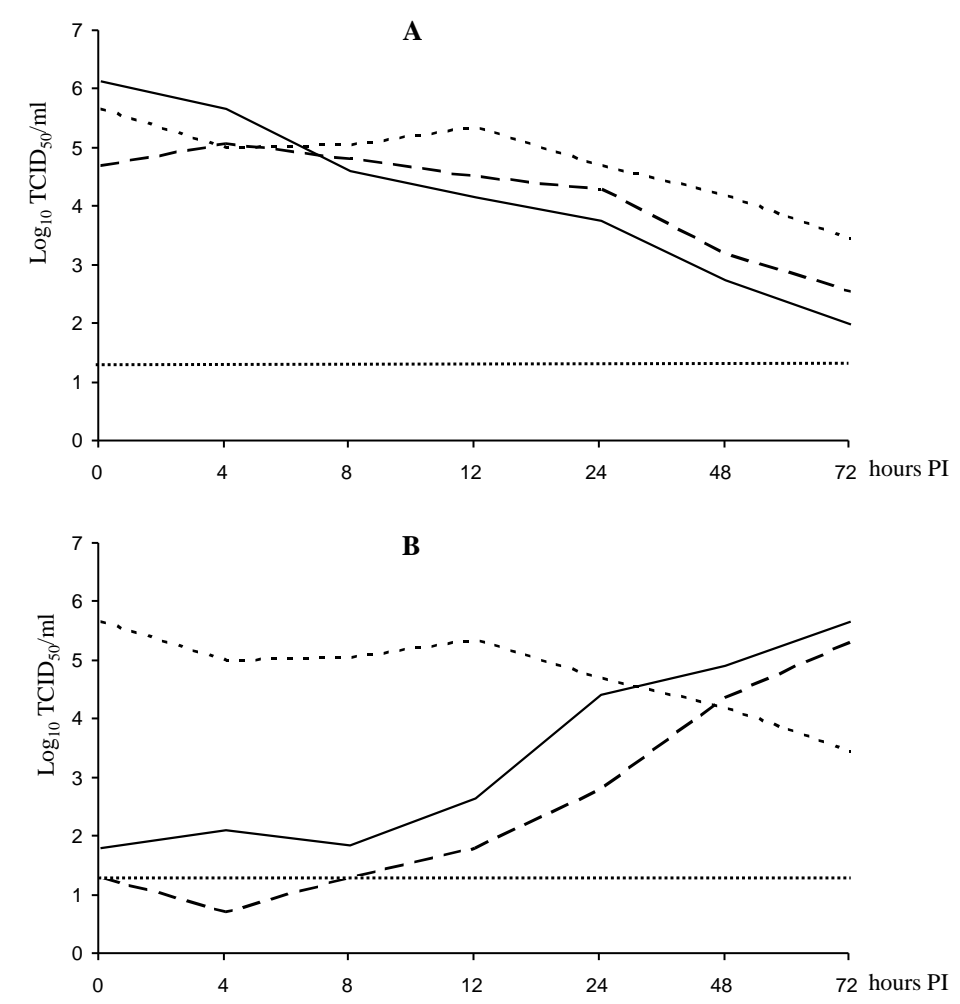

Fig. (4). Growth curves of PRCV in porcine alveolar macrophages (A) and primary lung epithelial cells (B). The full line represents the mean extracellular titre and the long-dashed line represents the mean intracellular titre. The short-dashed line is the inactivation curve and the dotted line is the detection limit. Collection of samples at 0 hours PI was performed after the washing step both for macrophages and primary lung epithelial cells.

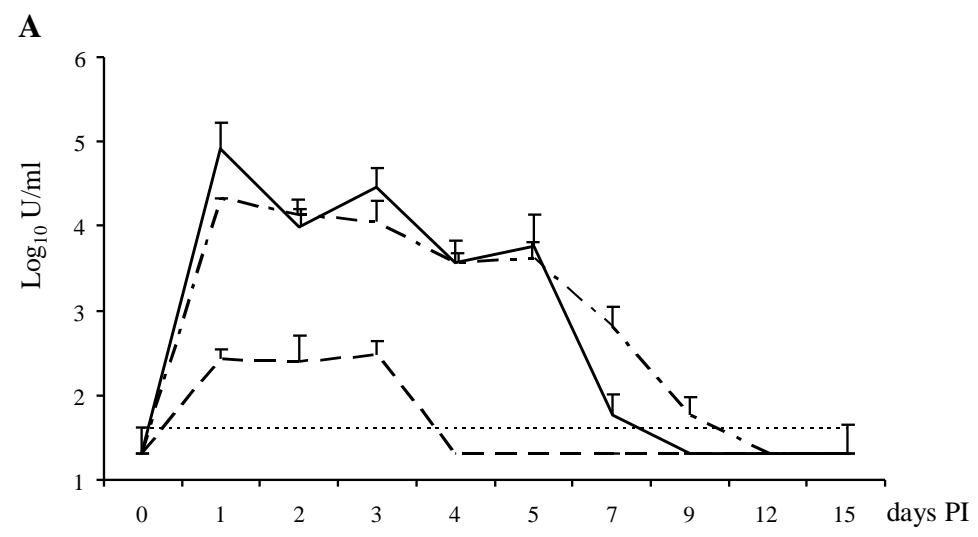

B

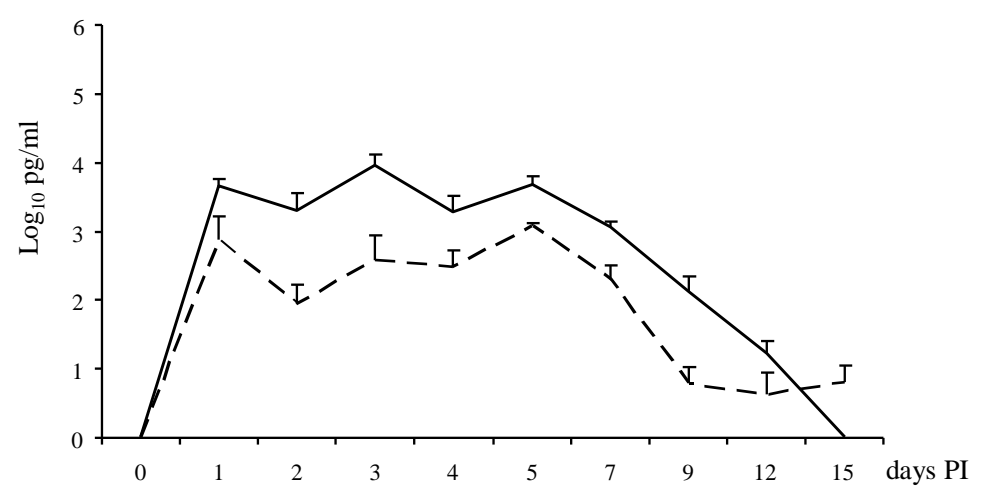

Fig. (5). Production of proinflammatory cytokines in the lungs during PRCV infection. Each line represents the mean of the individual values of 3 animals per time point. (A) Titres of IFN- $\alpha$ (full line), IL-6 (dash-and-dotted line) and TNF- $\alpha$ (dashed line). The dotted line represents the detection limit of the bioassays. (B) Titres of IFN- $\gamma$ (dashed line) and IL-12 p40 subunit (full line). Inflammatory cytokines were mainly found during the first 3 to 5 days of infection, except for IFN- $\gamma$ and IL-12, which were also found in high amounts at 7 DPI. 

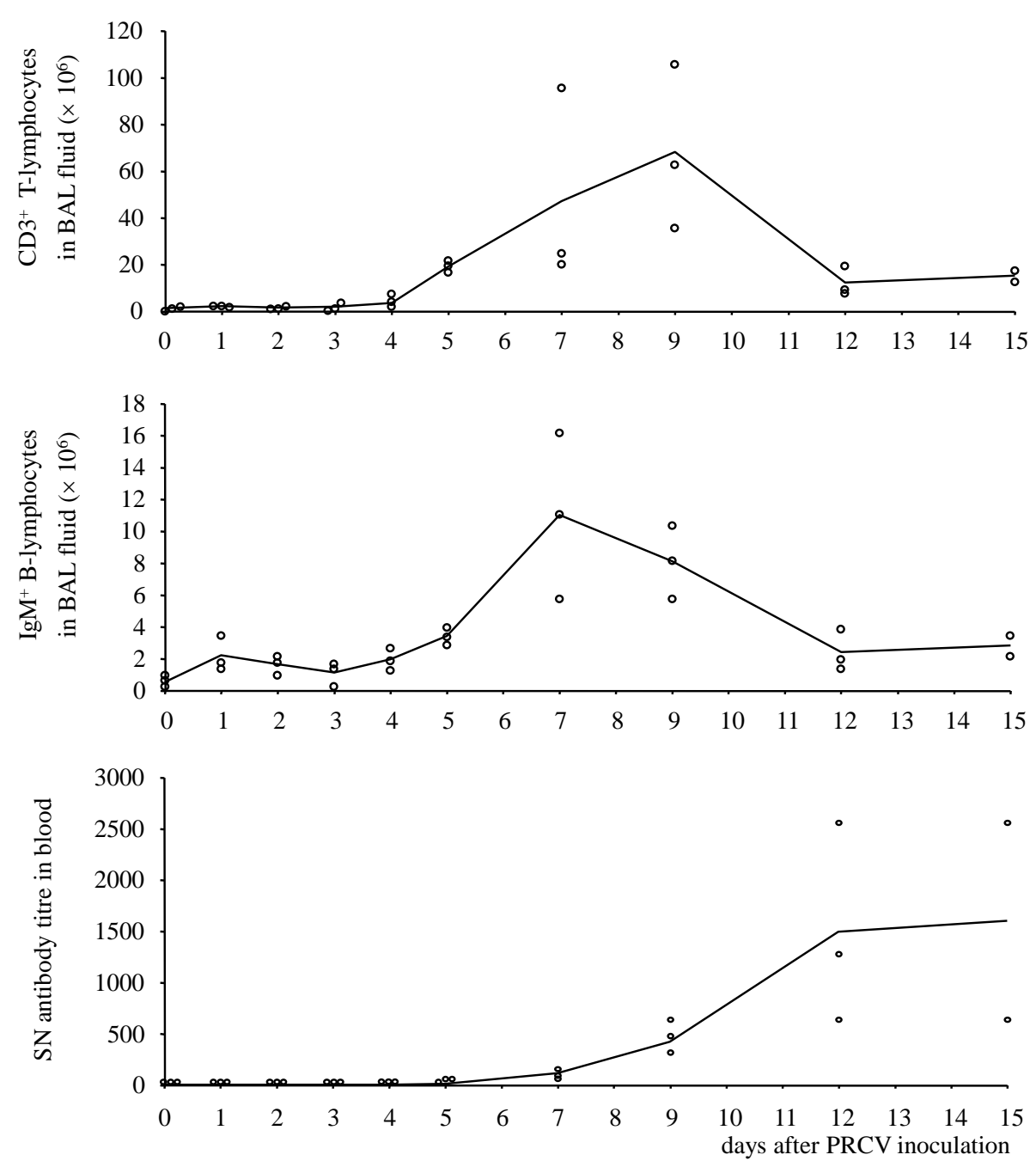

Fig. (6). Evolution of neutralising antibodies in the sera and lymphocyte numbers in the BAL fluids during PRCV infection. The dots represent the values of the individual pigs, whereas the full line represents the mean value. Anti-PRCV antibodies and increased numbers of lymphocytes were detectable from 7 and 5 DPI on respectively.

concluded that a Korean PRCV strain replicated primarily in interstitial macrophages. It is possible that the cell tropism differs between different PRCV strains, but on the other hand care should be taken when making conclusions about the cell tropism based on morphological data alone.

Similarly to previous experimental studies $[1,13,14]$, in our study most pigs did not develop clinical symptoms during the first 3-4 days after inoculation. Half of the pigs showed one or more signs of respiratory disease (abdominal thumping and/or tachypnoea) or depression at later stage of infection (5-8 DPI, with a peak at 7 DPI). Clinical signs were transient and disappeared between 9 and 15 DPI. This is in accordance with the observation of Duret and co-workers, who have seen respiratory symptoms between 7 and 8 DPI in specific pathogen free (SPF) pigs inoculated with a French PRCV-isolate [10]. For unknown reasons some researchers did observe respiratory symptoms with the same French isolate [12] or an isolate from The Netherlands [11] in the beginning of infection. Despite causing a mild or subclinical infection, PRCV is a relatively good inducer of several proinflammatory cytokines, including IFN- $\alpha$ and IL-6 [14, 42]. Now we have also found high levels of IFN- $\gamma$ and IL-12 during the first 5-7 DPI. All these cytokines are pleiotropic and can have many different biological effects depending on their concentration, the local microenvironment and the type of cells they affect. Most of them have been linked with disease in pigs (reviewed in [43]). In our study, however, we did not see a clear temporal association or individual correlations between those cytokines and disease during PRCV infection. We have previously shown that swine influenza virus, which produces clear respiratory symptoms in contrast to PRCV, induces a higher and more rapid production of proinflammatory cytokines $[16,44]$. It is possible that cytokines produced during PRCV infection do not reach sufficient levels to induce disease. Moreover, when PRCVinfected pigs are exposed to a secondary cytokine inducer, such as a lipopolysaccharide, they develop six- to tenfold higher amounts of IL-1 and TNF- $\alpha$ in the lungs than after inoculation with PRCV alone [42, 45]. This overproduction of cytokines also coincides with a sudden appearance of high fever, depression, tachypnoea and dyspnoea [42, 45]. This suggests that massive production of proinflammatory cytokines, or perhaps other factors in addition to cytokines are necessary for the development of clinical symptoms. 
PRCV infection in pigs has previously been suggested as a good model for studying the effect of corticosteroids on severe acute respiratory syndrome coronavirus (SARS-CoV) infection in humans [46]. Chen and Subbarao have done an extensive summary on currently available knowledge of SARS immunobiology [47]. Despite the fact that SARS-CoV causes severe illness in humans and is lethal in $10 \%$ of the cases, in contrast to PRCV in pigs, which is usually mild or subclinical, there are some similarities between the courses of these two infections. SARS-CoV starts as a mild pneumonia and clinical worsening typically appears at a late stage of infection ( $>1$ week), when virus load in the lungs starts to decrease and virus specific antibodies appear in the circulation. Respiratory dysfunction is caused by diffuse alveolar damage (DAD), which is believed to be triggered by an immunopathological reaction $[48,49]$. In PRCV we have seen also DAD appearing at 7-9 DPI when antibodies were already detectable in the blood (Fig. 6). Both PRCV and SARS-CoV seem to target predominantly type 2 pneumocytes in the lungs $[50,51]$. Conflicting reports on the ability of SARS-CoV to infect macrophages have been discussed in the above mentioned review article [47]. There is still very limited information about the induction of cytokines by SARS-CoV in the lungs of humans. However, the fact that cytokines have been found in sera from SARS patients during early stage of infection (reviewed in [47]) suggests that there may be enhanced cytokine production in the lungs as well. So far, the cytokine profiles in the lungs have been examined only in autopsy material from SARS patients that have died from acute respiratory distress at later stage of infection. The low levels of proinflammatory cytokines found in these cases may not necessarily reflect the cytokine production in the acute stage of infection. Therefore, we can not rule out the possibility that high levels of proinflammatory cytokines may be produced in the lungs during the acute stage of SARS-CoV infection in humans, as are during $\mathrm{PRCV}$ infection in pigs.

\section{CONCLUSIONS}

To conclude, we found that the type 2 pneumocyte is the main target cell of the examined Belgian isolate of PRCV, in the lungs of pigs. This observation together with the histopathological findings and the examination of the cytokine profile in the lungs at the later stages of infection add to the general knowledge about the pathogenesis of PRCV in its natural host. This lays a basis for a better comparison between the pathogeneses of PRCV and other coronaviruses, and gives further support to the use of PRCV infection in pigs as a model for SARS-CoV infection in humans.

\section{ACKNOWLEDGEMENTS}

The authors would like to thank Fernand De Backer, Nele Dennequin, Peter Meerts, Geert Opsomer and Lieve Sys for their excellent technical assistance. This work was supported by grant 1R01 AI060739-01 from the National Institutes of Health, NIH, USA.

\section{REFERENCES}

[1] Pensaert M, Callebaut P, Vergote J. Isolation of a porcine respiratory, non-enteric coronavirus related to transmissible gastroenteritis. Vet Q 1986; 8: 257-261.

[2] Wesley R, Woods R, Hill H, Biwer J. Evidence for a porcine respiratory coronavirus, antigenically similar to transmissible gastroen- teritis virus, in the United States. J Vet Diagn Invest 1990; 2: 312317.

[3] Hill H, Biwer J, Wood R, Wesley R. Porcine respiratory coronavirus isolated from two U.S. swine heards. In Proceedings of the American Association of Swine Practitioners, Des Moines, Iowa, 1990, p. 333.

[4] Laude H, Van Reeth K, Pensaert M. Porcine respiratory coronavirus: molecular features and virus-host interactions. Vet Res 1993; 24: $125-150$.

[5] Pensaert M, Cox E, Van Deun K, Callebaut P. A seroepizootological study of porcine respiratory coronavirus in Belgian swine population. Vet Q 1993; 15: 16-20.

[6] Cox E, Hooyberghs J, Pensaert MB. Sites of replication of a porcine respiratory coronavirus related to transmissible gastroenteritis virus. Res Vet Sci 1990; 48: 165-169.

[7] Sirinarumitr T, Paul PS, Kluge JP, Halbur PG. In situ hybridization technique for the detection of swine enteric and respiratory coronaviruses, transmissible gastroenteritis virus (TGEV) and porcine respiratory coronavirus (PRCV), in formalin-fixed paraffinembedded tissues. J Virol Methods 1996; 56: 149-160.

[8] O'Toole D, Brown I, Bridges A, Cartwright SF. Pathogenicity of experimental infection with 'pneumotropic' porcine coronavirus. Res Vet Sci 1989; 47: 23-29.

[9] Ahn K, Chae C, Kweon CH. Immunohistochemical identification of porcine respiratory coronavirus antigen in the lung of conventional pigs. Vet Pathol 1997; 34: 167-169.

[10] Duret C, Brun A, Guilmoto H, Dauvergne M. Isolation, identification and pathogenicity in pigs of a coronavirus related to the transmissible gastroenteritis virus. Rec Méd Vét 1988; 164: 221-226.

[11] van Nieuwstadt AP, Pol JM. Isolation of a TGE virus-related respiratory coronavirus causing fatal pneumonia in pigs. Vet Rec 1989; 124: 43-44.

[12] Vannier P. Disorders induced by the experimental infection of pigs with the porcine respiratory coronavirus (P.R.C.V.). Zentralbl Veterinarmed B 1990; 37: 177-180.

[13] Halbur PG, Paul PS, Vaughn EM, Andrews JJ. Experimental reproduction of pneumonia in gnotobiotic pigs with porcine respiratory coronavirus isolate AR310. J Vet Diagn Invest 1993; 5: 184188.

[14] Van Reeth K, Labarque G, Nauwynck H, Pensaert M. Differential production of proinflammatory cytokines in the pig lung during different respiratory virus infections: correlations with pathogenicity. Res Vet Sci 1999; 67: 47-52.

[15] Van Reeth K, Van Gucht S, Pensaert M. In vivo studies on cytokine involvement during acute viral respiratory disease of swine: troublesome but rewarding. Vet Immunol Immunopathol 2002; 87: 161-168.

[16] Van Reeth K, Van Gucht S, Pensaert M. Correlations between lung proinflammatory cytokine levels, virus replication, and disease after swine influenza virus challenge of vaccination-immune pigs. Viral Immunol 2002; 15: 583-594.

[17] O'Neill L, Gearing A, Callard R. In: Fitzgerald K. Ed. Interferongamma, Academic Press, London, 2001; 322-327.

[18] Trinchieri G. Interleukin-12: a proinflammatory cytokine with immunoregulatory functions that bridge innate resistance and antigen-specific adaptive immunity. Annu Rev Immunol 1995; 13: 251-276.

[19] Gately M, Renzetti L, Magram J, et al. The interleukin12/interleukin-12-receptor system: role in normal and pathologic immune responses. Annu Rev Immunol 1998; 16: 495-521.

[20] Ozmen L, Aguet M, Trinchieri G, Garotta G. The in vivo antiviral activity of interleukin-12 is mediated by gamma interferon. J Virol 1995; 69: 8147-8150.

[21] Carter Q, Curiel R. Interleukin-12 (IL-12) ameliorates the effects of porcine respiratory and reproductive syndrome virus (PRRSV) infection. Vet Immunol Immunopathol 2005; 107: 105-118.

[22] Van Reeth K, Pensaert MB. Porcine respiratory coronavirusmediated interference against influenza virus replication in the respiratory tract of feeder pigs. Am J Vet Res 1994; 55: 1275-1281.

[23] Van Gucht S, Van Reeth K, Nauwynck H, Pensaert M. Porcine reproductive and respiratory syndrome virus infection increases CD14 expression and lipopolysaccharide-binding protein in the lungs of pigs. Viral Immunol 2005; 18: 116-126.

[24] Jimenez G, Correa I, Melgosa MP, Bullido MJ, Enjuanes L. Critical epitopes in transmissible gastroenteritis virus neutralization. J Virol 1986; 60: 131-139. 
[25] Vanderheijden N, Delputte PL, Favoreel HW, et al. Involvement of sialoadhesin in entry of porcine reproductive and respiratory syndrome virus into porcine alveolar macrophages. J Virol 2003; 77: 8207-8215.

[26] Schlichenmaier H, Steffl M, Sinowatz F, Amselgruber WM. Expression of cytokeratin 18 during pre- and post-natal porcine lung development. Anat Histol Embryol 2002; 31: 273-277.

[27] Paananen R, Glumoff V, Sormunen R, Voorhout W, Hallman M. Expression and localization of lung surfactant protein B in Eustachian tube epithelium. Am J Physiol Lung Cell Mol Physiol 2001; 280: L214-L220.

[28] Labarque GG, Nauwynck HJ, Van Reeth K, Pensaert MB. Effect of cellular changes and onset of humoral immunity on the replication of porcine reproductive and respiratory syndrome virus in the lungs of pigs. J Gen Virol 2000; 81: 1327-1334.

[29] Dewerchin HL, Cornelissen E, Nauwynck HJ. Replication of feline coronaviruses in peripheral blood monocytes. Arch Virol 2005; 150: 2483-2500.

[30] Lin C, Holland RE Jr, Williams NM, Chambers TM. Cultures of equine respiratory epithelial cells and organ explants as tools for the study of equine influenza virus infection. Arch Virol 2001; 146: 2239-2247.

[31] La Bonnardière C, Laude H. High interferon titre in newborn pig intestine during experimentally induced viral enteritis. Infect Immun 1981; 32: 28-31.

[32] Helle M, Boeije L, Aarden LA. Functional discrimination between interleukin 6 and interleukin 1. Eur J Immunol 1988; 18: 15351540.

[33] Novelli F, Casanova J. The role of IL-12, IL-23 and IFN- $\gamma$ in immunity to viruses. Cytokine Growth Factor Rev 2004; 15: 367-377.

[34] Watford W, Hissong B, Bream J, Kanno Y, Muul L, O'Shea J. Signaling by IL-12 and IL-23 and the immunoregulatory roles of STAT4. Immunol Rev 2004; 202: 139-156.

[35] Bastos K, Marinho C, Barboza R, Russo M, Alvarez J, Lima M. What kind of message does IL-12/IL-23 bring to macrophages and dendritic cells? Microbes Infect 2004; 6: 630-636.

[36] Van Zaane D, Hulst MM. Monoclonal antibodies against porcine immunoglobulin isotypes. Vet Immunol Immunopathol 1987; 16: 23-36.

[37] Kirkham PA, Takamatsu H, Yang H, Parkhouse RM. Porcine CD3 epsilon: its characterization, expression and involvement in activation of porcine T lymphocytes. Immunology 1996; 87: 616-623.

[38] Voets MT, Pensaert MB, Rondhuis PR. Vaccination of pregnant sows against transmissible gastroenteritis using two attenuated vi- rus strains and different inoculation routes. Vet Q 1980; 2: 211219.

[39] Castranova V, Rabovsky J, Tucker JH, Miles PR. The alveolar type II epithelial cell: a multifunctional pneumocyte. Toxicol Appl Pharmacol 1988; 93: 472-483.

[40] Fehrenbach H. Alveolar epithelial type II cell: defender of the alveolus revisited. Respir Res 2001; 2: 33-46.

[41] Laude H, Charley B, Gelfi J. Replication of transmissible gastroenteritis coronavirus (TGEV) in swine alveolar macrophages. J Gen Virol 1984; 65: 327-332

[42] Van Gucht S, Atanasova K, Barbé F, Cox E, Pensaert M, Van Reeth K. Effect of porcine respiratory coronavirus infection on lipopolysaccharide recognition proteins and haptoglobin levels in the lungs. Microbes Infect 2006; 8: 1492-1501.

[43] Van Reeth K, Nauwynck H. Proinflammatory cytokines and viral respiratory disease in pigs. Vet Res 2000; 31: 187-213.

[44] Van Reeth K, Nauwynck H, Pensaert M. Bronchoalveolar interferon-alpha, tumor necrosis factor-alpha, interleukin-1, and inflammation during acute influenza in pigs: a possible model for humans? J Infect Dis 1998; 177: 1076-1079.

[45] Van Reeth K, Nauwynck H, Pensaert M. A potential role for tumor necrosis factor-alpha in synergy between porcine respiratory coronavirus and bacterial lipopolysaccharide in the induction of respiratory disease in pigs. J Med Microbiol 2000; 49: 613-620.

[46] Jung K, Alekseev KP, Zhang X, Cheon DS, Vlasova AN, Saif LJ. Altered pathogenesis of porcine respiratory coronavirus in pigs due to immunosuppressive effects of dexamethasone: implications for corticosteroid use in treatment of severe acute respiratory syndrome coronavirus. J Virol 2007; 81: 13681-13693.

[47] Chen J, Subbarao K. The immunobiology of SARS. Annu Rev Immunol 2007; 25: 443-472

[48] Nicholls JM, Poon LL, Lee KC, et al. Lung pathology of fatal severe acute respiratory syndrome. Lancet 2003; 361: 1773-1778.

[49] Lin YS, Lin CF, Fang YT, et al. Antibody to severe acute respiratory syndrome (SARS)-associated coronavirus spike protein domain 2 cross-reacts with lung epithelial cells and causes cytotoxicity. Clin Exp Immunol 2005; 141: 500-508.

[50] Hsiao CH, Chang MF, Hsueh PR, Su IJ. Immunohistochemical study of severe acute respiratory syndrome-associated coronavirus in tissue sections of patients. J Formos Med Assoc 2005; 104: 150156.

[51] Shieh WJ, Hsiao CH, Paddock CD, et al. Immunohistochemical, in situ hybridization, and ultrastructural localization of SARSassociated coronavirus in lung of a fatal case of severe acute respiratory syndrome in Taiwan. Hum Pathol 2005; 36: 303-309.

Received: June 30, 2008

Revised: July 18, 2008

Accepted: August 6,2008

(C) Atanasova et al.; Licensee Bentham Open.

This is an open access article licensed under the terms of the Creative Commons Attribution Non-Commercial License (http://creativecommons.org/licenses/by$\mathrm{nc} / 3.0 /$ ) which permits unrestricted, non-commercial use, distribution and reproduction in any medium, provided the work is properly cited. 